\title{
Intramural hematoma of the colon caused by double-balloon enteroscopy in a patient with chronic disseminated intravascular coagulation
}
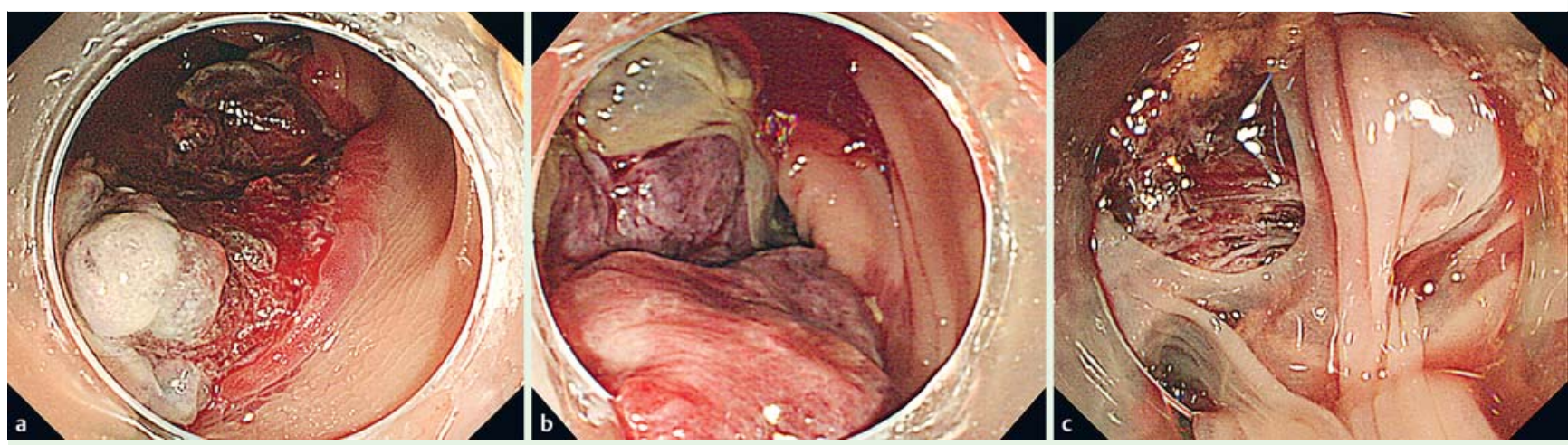

Fig. 1 Views during emergency colonoscopy showing an intramural hematoma at the junction of the descending and sigmoid colon, with rupture and bleeding into the surrounding mucosa.
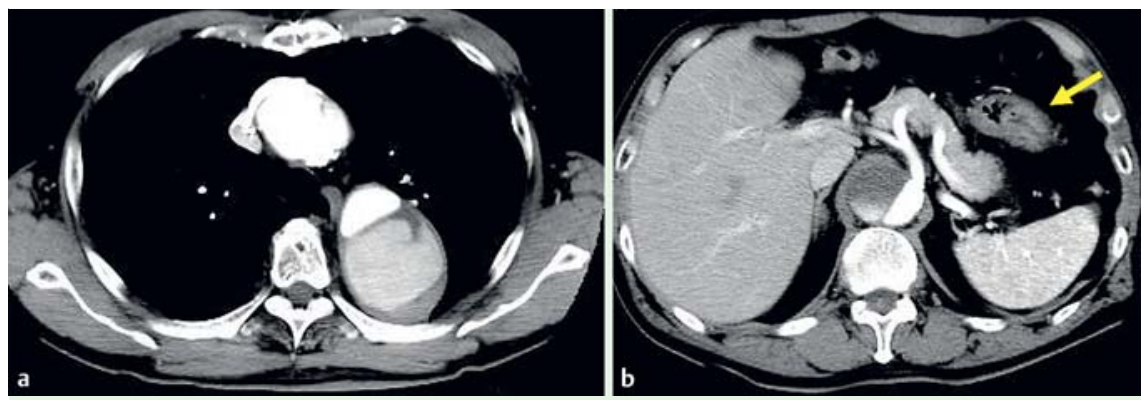

Fig. 2 Contrast-enhanced computed tomography (CT) scans showing an aortic dissection running from: a the ascending aorta to; $\mathbf{b}$ the abdominal aorta, along with a mass partially obstructing the sigmoid colon (yellow arrow).

A 63-year-old man with a history of surgery for thoracic aortic dissection was transferred to our hospital with obscure gastrointestinal bleeding (OGIB) and bloody stools. Laboratory examination revealed the following results: hemoglobin, $9.9 \mathrm{~g} / \mathrm{dL}$; platelets, $94000 / \mu \mathrm{L}$; creatinine, $1.29 \mathrm{mg} / \mathrm{dL}$. Video capsule endoscopy following anterograde and retrograde double-balloon enteroscopy (DBE) could not identify the bleeding source.

Fresh bloody stools recurred 4 days after the resumption of feeding and the patient required transfusion. Emergency colonoscopy revealed an intramural hematoma in the sigmoid colon, with rupture and bleeding into the surrounding mucosa ( $\bullet$ Fig. 1 ). Contrast-enhanced computed tomography (CT) revealed a dissection of the abdominal aorta ( $\bullet$ Fig. 2 ). Laboratory data indicated disseminated intravascular coagulation (DIC): platelets, $96000 / \mu \mathrm{L}$; pro- thrombin time, 13.5 seconds; fibrinogen, $69 \mathrm{mg} / \mathrm{dL}$; fibrin/fibrinogen degradation products, $105 \mu \mathrm{g} / \mathrm{dL}$; D-dimer, $99 \mu \mathrm{g} / \mathrm{dL}$; plasmin- $\alpha_{2}$-plasmin inhibitor complex, $11.4 \mu \mathrm{g} / \mathrm{mL}$; thrombin-antithrombin III complex, $49.5 \mathrm{ng} / \mathrm{mL}$. We diagnosed an intramural hematoma of the colon due to chronic DIC associated with aortic dissection.

The patient was not a candidate for surgery for the aortic dissection because of his comorbidities. Continuous intravenous heparin (15000 units/day) improved the laboratory abnormalities. Follow-up colonoscopy 16 days after the initial treatment showed healing ulceration ( $\bullet$ Fig. 3 ). The patient was changed to oral warfarin, following which no recurrent bleeding was observed.

Bleeding associated with DBE is rare and mostly follows polypectomy or biopsy [1]. Intramural hematoma of the colon is

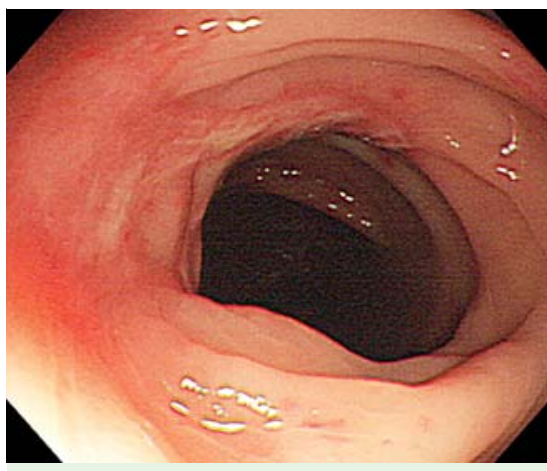

Fig.3 Follow-up colonoscopy showing improvement of the hematoma and healing ulceration 16 days after treatment.

rare but can be the result of blunt trauma typically in the presence of anticoagulant therapy or other hematologic disease [2]. In this case, DBE compressed the mucosa, resulting in an intramural hematoma of the colon, under conditions of chronic DIC, which is a rare finding often associated with aortic aneurysm and dissection [3]. Surgery is the primary treatment to eliminate the cause but heparin has been reported to treat chronic DIC effectively [3]. We recommend careful examination of coagulation studies prior to DBE in patients with OGIB and an aortic aneurysm or dissection.

Endoscopy_UCTN_Code_CPL_1AI_2AD

Competing interests: None 
Yasuaki Nagami, Yasuhiro Fujiwara, Masafumi Yamamura, Masatsugu Shiba, Toshio Watanabe, Kazunari Tominaga, Tetsuo Arakawa

Department of Gastroenterology, Osaka City University Graduate School of Medicine, Osaka, Japan

\section{References}

1 Nakayama S, Tominaga $K$, Obayashi $T$ et al. The prevalence of adverse events associated with double-balloon enteroscopy from a single-centre dataset in Japan. Dig Liver Dis 2014; 46: 706-709

2 Liu Y, YangS, Tong Q. Spontaneous intramural hematoma of colon. Clin Gastroenterol Hepatol 2012; 10: e38

3 Yamamoto K, Ito $\mathrm{H}$, Hiraiwa $\mathrm{T}$ et al. Effects of nafamostat mesilate on coagulopathy with chronic aortic dissection. Ann Thorac Surg 2009; 88: 1331 - 1333

\section{Bibliography}

Dol http://dx.doi.org/

10.1055/s-0042-104276

Endoscopy 2016; 48: E105-E106

(c) Georg Thieme Verlag KG

Stuttgart · New York

ISSN 0013-726X

\section{Corresponding author} Yasuaki Nagami, MD, PhD

Department of Gastroenterology

Osaka City University Graduate School of Medicine 1-4-3, Asahimachi, Abeno-ku

Osaka, 545-8585

Japan

Fax: +81-6-66453813

yasuaki1975@hotmail.com 